\title{
Differential Responses of Two Ecologically Similar Case-Bearing Caddisfly Species to a Fish Chemical Cue: Implications for a Coexistence Mechanism
}

\section{$\operatorname{AUTHOR}(S)$ :}

Okano, Jun-ichi; Tayasu, Ichiro; Nakano, Shin-ichi; Okuda, Noboru

\section{CITATION:}

Okano, Jun-ichi ... [et al]. Differential Responses of Two Ecologically Similar Case-Bearing Caddisfly Species to a Fish Chemical Cue: Implications for a Coexistence Mechanism. Zoological Science 2017, 34(6): 461-467

\section{ISSUE DATE:}

2017-12-01

URL:

http://hdl.handle.net/2433/252791

\section{RIGHT:}

(c) 2017 Zoological Society of Japan; 許諾条件に基づいて掲載していま す。 


\title{
Differential Responses of Two Ecologically Similar Case-Bearing Caddisfly Species to a Fish Chemical Cue: Implications for a Coexistence Mechanism
}

\author{
Jun-ichi Okano $^{1 *}$, Ichiro Tayasu ${ }^{1,2}$, Shin-ichi Nakano ${ }^{1}$, and Noboru Okuda ${ }^{1,2}$ \\ ${ }^{1}$ Center for Ecological Research, Kyoto University, 509-3, 2-chome, Hirano, \\ Otsu, Shiga 520-2113, Japan \\ ${ }^{2}$ Research Institute for Humanity and Nature, 457-4 Motoyama, \\ Kamigamo, Kyoto 603-8047, Japan
}

\begin{abstract}
The mechanisms for the coexistence of multiple species occupying the same ecological niche are often puzzling. Predator effects on competitively superior species is one possible mechanism. In this study, we tested whether the presence of size-selective predators (fishes) acts as a mechanism for the coexistence of two species of case-bearing caddisfly larvae, Perissoneura paradoxa and Psilotreta kisoensis (Odontoceridae, Trichoptera). The larvae of these two species have similar ecological and life history traits except their body size, and they have been found to coexist only in habitats shared with predatory fishes. Experiments on intra and interspecific competition revealed that the larger Pe. paradoxa always outcompeted the smaller Ps. kisoensis in the absence of predatory fishes, suggesting that $P$ e. paradoxa performed intra-guild predation on Ps. kisoensis. We also conducted experiments to examine how strongly each of these species responded in terms of case repair with/without a predator chemical cue after their cases were partly dismantled. Perissoneura paradoxa exhibited a stronger case repair response in the presence of a predator chemical cue than that exhibited by $P$ s. kisoensis, suggesting that $P$ e. paradoxa is more vulnerable to fish predation, probably because their body size is in the preferred prey range of fishes. We suggest that the presence of predators works in the favor of smaller, subordinate species through size-selective predator effects, enabling these two competitive species to coexist in the same habitat.
\end{abstract}

Key words: chemical cue, intra-guild predation, competitive exclusion, predator-mediated coexistence

\section{INTRODUCTION}

A major challenge in ecological studies is understanding how numerous species are able to coexist and interact. Puzzling is the mechanism behind the coexistence of multiple species sharing the same ecological niche, which is contrary to Gause's law of competitive exclusion (Gause, 1934; Hardin, 1960). Selective predation on a competitively superior species is one of the most prevailing factors that permits the existence of inferior species, as it reduces interspecific competition (Paine, 1966; Taniguchi and Tokeshi, 2004; Koivisto et al., 2007). Thus, evaluating predator effects is important to revealing the mechanisms enabling coexistence.

Research into antipredator behavior in response to chemical cues emitted by predators has provided important clues for understanding the evolutional history of prey species in relation to predators in many organisms, such as snails (Bourdeau, 2012), tadpoles (Hettyey et al., 2015), crayfish (Shave et al., 1994), shrimp (Covich et al., 2009), and insects (Cerezer et al., 2016). In addition, it has recently been shown that protective responses could significantly

\footnotetext{
* Corresponding author. E-mail: j.oj.055222@gmail.com doi:10.2108/zs160207
}

affect trophic cascades through their non-consumptive effects (Relyea, 2000; Trussell et al., 2006; Reynolds and Bruno, 2013). Thus, a prey protective response can be a useful indicator to estimate even complex trophic and competitive interactions.

In general, the protective responses of prey can be classified as anatomical (e.g., prickles on body surface and bulgy body; Kishida and Nishimura, 2004) or behavioral (e.g. pausing, drifting and taking refuge; Alvarez et al., 2014). Anatomical changes often take a long time to develop and are irreversible. On the other hand, behavioral responses are temporary, but the response is quick and reversible. Protective external structures (e.g., nests, burrows, retreats, and cases) built by organisms can be treated as anatomical traits that are extended by the behavioral phenotype (Boyero, 2011). These intermediate phenotypic traits can be quickly developed and are also long-lasting. Therefore, by evaluating the responses of construction behavior, it may be possible to easily estimate predation pressure on a prey species.

The larvae of many caddisfly species (order Trichoptera) construct portable cases in a variety of forms and shapes using materials derived from the sediment (Wiggins, 2004). Some species of case-bearing caddisfly are known to immediately switch their case material from soft material to a more rigid material under the presence of predators (Boyero et al., 
2006; Boyero, 2011). In addition, these studies have reported that the switching rate of case material and the rapidity of case construction varied depending on the predator species. This indicates the possibility that we can estimate the potential predation risk to a caddisfly species by evaluating case-building responses.

The larvae of two case-bearing caddisfly species, Perissoneura paradoxa McLachlan and Psilotreta kisoensis Iwata (Odontoceridae, Trichoptera), are widely distributed on Honshu Island, Japan. While their biology is quite similar, there are clear differences in body size where the dry weight of $P$ e. paradoxa is approximately four times that of $P S$. kisoensis. In this study, we first show that these two species can coexist in a shared habitat only when under predatory pressure. We predict that the size-selective predator effect of fish can be a proximate factor in maintaining the stable coexistence of these two caddisfly species. To test this prediction, we experimentally analyzed the inferior-to-superior relationship between the two species under a fishless condition, and their differential antipredator behavior in response to a fish chemical cue. The present study provides important insights for better understanding the factors that maintain the stable coexistence of ecologically similar species.

\section{MATERIALS AND METHODS}

\section{Study organisms}

The genus Perissoneura is endemic to Japan (Nozaki et al., 1994). The biology and ecology of this genus are closely similar to those of Psilotreta, including a shared habitat (confined to springfed and headwater mountain stream pools), life cycle (1-2 years voltine; emergence during May; Okano unpublished), feeding habit (cannibalistic scavenger), behavior of settling in the sediment (Wiggins, 2004), case shape (simple cylindrical case constructed from sediment sand), and criterion of case material choice (Okano et al., 2011). However, the body size of Pe. paradoxa is clearly larger than that of $P$ s. kisoensis; the maximum body dry weight is 20 $\mathrm{mg}$ in Pe. paradoxa and $5 \mathrm{mg}$ in Ps. kisoensis (Okano et al., 2011). The two species often exhibit size-dependent cannibalism and intra-guild predation (Okano et al., 2016; Okano unpublished), wherein a larger larva will eat a smaller one by invading its case.

\section{Natural habitat}

We surveyed the natural habitat distribution of $P e$. paradoxa and Ps. kisoensis larvae on Honshu Island from 2003 to 2014. In each habitat, the presence/absence of predatory fish was confirmed by visual observation and the kick-net method for $1 \mathrm{~h}$ continuously. This method for confirming fish absence was sufficient as larval habitats were typically small streams less than $2 \mathrm{~m}$ wide and $30 \mathrm{~cm}$ deep. We confirmed the absence of fish at certain sites for a period of at least four years.

\section{Determination of inter-specific com- petition}

To evaluate the interaction between Pe. paradoxa and Ps. kisoensis in the absence of predatory fish, we measured larval survivability and growth under a shared habitat and separated incubation in a laboratory setting. The incubation conditions (larval localities, individual number, and sediment sand types) are described in Table 1. In midMay 2014, we collected Pe. paradoxa pupae from Mt. Tsukuba (Site 2 in Table 2) and Ps. kisoensis pupae from Mt. Maya (Site 4) and Mt. Gozen (Site 5). In the laboratory, each pupal population was separately incubated in a $40 \times 45 \times 20 \mathrm{~cm}$ aquarium tank. We obtained egg clutches from the emerged adults at the end of May (23 clutches from $P$ e. paradoxa from Site 2, 7 from $P$ s. kisoensis from Site 4, and 13 from $P$. kisoensis from Site 5). Next generation larvae hatched between June 10 and 14 and were incubated for two weeks in $28 \times$ $20 \times 8 \mathrm{~cm}$ containers, paved with natural sediment sand from Site 5 , and submerged in aquarium tanks. We started the incubation experiment on June 28. Immature larvae of each population were randomly divided into $13 \times 13 \times 5 \mathrm{~cm}$ containers according to the setting conditions. Either of the two species was introduced into a container for the separated condition and both species were introduced together into a container for the sympatric condition. We placed one of two types of artificial sand $(70 \mathrm{ml}$ of glass or ceramic sand) in each container, prepared according to previous studies (Okano et al., 2011; Okano et al., 2012). Using the artificial sand as case material, larvae enlarged their cases by extending the anterior end. Rough surface ceramic sand (microscale roughness, i.e., surface texture) is less preferable than smooth surface glass sand for case material, as the rough inner wall decreases larval respiration efficiency by increasing the friction between the abdomen and the case wall, which reduces their growth and increases their metabolic cost and mortality potential (Williams and Pennak, 1980; Okano and Kikuchi, 2009; Okano et al., 2016). Thus, we used the two types of sand to examine the physiological effects on competition based on case material quality. These containers were submerged in a large aquarium tank. During the incubation period, each larva was fed $0.02 \mathrm{mg}$ of fish meal (Tetra Fin; Tetra Co., Melle, Germany) once every three days. We did not adjust the food amount according to the decreasing number of individuals. On 30 July, we measured larval survivability and aperture diameter (AD) of the anterior end of the case in each container. AD data were transformed to larval body weight (DW $\mathrm{mg}$ ) using the relationship derived from our previous data (Eq. 1 and 2; Okano et al., 2011):

$$
\begin{aligned}
& \text { Body weight of Pe.paradoxa } \\
& =0.111 \times A D^{2.96}\left(n=119, r^{2}=0.804\right) \\
& \text { Body weight of } P \text { s. kisoensis } \\
& =0.323 \times A D^{2.15}\left(n=115, r^{2}=0.620\right)
\end{aligned}
$$

\begin{tabular}{|c|c|c|c|c|}
\hline Species & Separated /Sympatric & Individual number & Sediment & Replicate number \\
\hline Pe. paradoxa & Separated & 55 & Glass & 1 \\
\hline Pe. paradoxa & Separated & 55 & Ceramic & 1 \\
\hline Pe. paradoxa & Separated & 110 & Glass & 1 \\
\hline Pe. paradoxa & Separated & 110 & Ceramic & 1 \\
\hline Ps. kisoensis (Site 4) & Separated & 110 & Glass & 1 \\
\hline Ps. kisoensis (Site 4) & Separated & 110 & Ceramic & 1 \\
\hline Ps. kisoensis (Site 5) & Separated & 110 & Glass & 1 \\
\hline Ps. kisoensis (Site 5) & Separated & 110 & Ceramic & 1 \\
\hline $\begin{array}{c}\text { Pe. paradoxa }+ \\
\text { Ps. kisoensis (Site 4) }\end{array}$ & Sympatric & $55: 55$ & Glass & 1 \\
\hline $\begin{array}{c}\text { Pe. paradoxa }+ \\
\text { Ps. kisoensis (Site 4) }\end{array}$ & Sympatric & $55: 55$ & Ceramic & 1 \\
\hline $\begin{array}{c}\text { Pe. paradoxa }+ \\
\text { Ps. kisoensis (Site 5) }\end{array}$ & Sympatric & $55: 55$ & Glass & 1 \\
\hline $\begin{array}{c}\text { Pe. paradoxa }+ \\
\text { Ps. kisoensis (Site 5) }\end{array}$ & Sympatric & $55: 55$ & Ceramic & 1 \\
\hline
\end{tabular}

We considered the difference in mortality between the sepa-

Table 1. Incubation conditions of Perrissoneura paradoxa and Psilotreta kisoensis larvae. 
Table 2. Presence or absence of Perrissoneura paradoxa and Psilotreta kisoensis larvae and predatory fish in a natural habitat.

\begin{tabular}{|c|c|c|c|c|c|c|}
\hline Site name & Site number & Lat/Long & Pe. paradoxa & Ps. kisoensis & Fish & Major fish species \\
\hline Mt. Aoba & Site $1^{*}$ & $38^{\circ} 15^{\prime} \mathrm{N} / 140^{\circ} 49^{\prime} \mathrm{E}$ & $x$ & ○ & $x$ & \\
\hline Mt. Tsukuba & Site 2 & $36^{\circ} 10^{\prime} \mathrm{N} / 140^{\circ} 7^{\prime} \mathrm{E}$ & O & $x$ & $x$ & \\
\hline Mt. Yokone & Site 3 & $38^{\circ} 4^{\prime} \mathrm{N} / 139^{\circ} 43^{\prime} \mathrm{E}$ & $x$ & o & $x$ & \\
\hline Mt. Gozen & Site 5 & $36^{\circ} 32^{\prime} \mathrm{N} / 140^{\circ} 19^{\prime} \mathrm{E}$ & 0 & $x$ & $x$ & \\
\hline Mt. Gozen & SSS of Site $5^{\star *}$ & (600 $\mathrm{m}$ from Site 5$)$ & $x$ & O & $x$ & \\
\hline Sekigahara & Site 6 & $35^{\circ} 22^{\prime} \mathrm{N} / 136^{\circ} 27^{\prime} \mathrm{E}$ & $x$ & O & $x$ & \\
\hline Sekigahara & 1.SSS of Site 6 & (85 $\mathrm{m}$ from Site 6 ) & ○ & $x$ & $x$ & \\
\hline Sekigahara & 2.SSS of Site 6 & (900 $\mathrm{m}$ from Site 6$)$ & O & $x$ & $x$ & \\
\hline Kakita & Site 7 & $35^{\circ} 6^{\prime} \mathrm{N} / 138^{\circ} 54^{\prime} \mathrm{E}$ & O & $x$ & 0 & amur minnow, sculpin, goby *** \\
\hline Mt. Maya & Site 4 & $34^{\circ} 43^{\prime} \mathrm{N} / 135^{\circ} 11^{\prime} \mathrm{E}$ & O & O & o & dark chub sculpin, goby \\
\hline Hiramizo & Site 8 & $35^{\circ} 82^{\prime} \mathrm{N} / 139^{\circ} 19^{\prime} \mathrm{E}$ & 0 & O & o & char, landlocked salmon **** \\
\hline Akashio & Site 9 & $35^{\circ} 87^{\prime} \mathrm{N} / 137^{\circ} 67^{\prime} \mathrm{E}$ & 0 & 0 & 0 & char \\
\hline
\end{tabular}

* Site1-7 correspond to site number in Okano et al. (2011).

** 'SSS of Site5' means habitat where is same stream system of Site5.

*** T. Nozaki (personal communicatin)

**** Yokota et al. (2013)

rated and sympatric-rearing conditions as larval death caused by intra-guild predation among the two species.

\section{Determining predator-mediated competition}

To evaluate the interaction between predatory fish and $P e$. paradoxa and $P$ s. kisoensis, we conducted case repair experiments under the presence/absence of predator chemical cues in a laboratory setting. On August 13, 2014, we collected Pe. paradoxa $(n=9)$ and Ps. kisoensis $(n=10)$ larvae and the predatory white spotted char (Salvelinus leucomaenis $n=1$ ) from the Akashio River (Site 9 in Table 2). River water was collected in two plastic bags at the same time. S. leucomaenis was placed in one of the bags for $4 \mathrm{~h}$, and we used this water as the source of predator chemical cues to induce the protective behavior among the caddisflies.

In the laboratory, the length and $A D$ of the anterior end of the larval cases were measured under magnification. Larvae were then grouped for two experimental treatments so as to prevent an uneven larval size. The first treatment represented the absence of predatory pressure ( $n=5$ each for Pe. paradoxa and Ps. kisoensis) and the second represented the presence of a predator $(P e$. paradoxa $n=4$ and Ps. kisoensis $n=5$ ). For all caddisfly larvae used in this experiment, the anterior portion of the larval case was removed (one-fourth of the case length) to induce case re-construction. Each larva was separately placed in a container measuring 3.5 $\mathrm{cm}$ in diameter and $1 \mathrm{~cm}$ in depth and $2 \mathrm{ml}$ of artificial glass sand was provided as case material. Following this, $10 \mathrm{ml}$ of river water was added to containers of the control (representing predator absence) and $4 \mathrm{ml}$ of river water plus $6 \mathrm{ml}$ of water from the bag that had contained $S$. leucomaenis was added to containers of the treatment condition (representing predator presence). All containers were placed under the eaves of the laboratory building. The experiment started at 6:00 PM on 13 August and ended at 4:00 PM the next day $(22 \mathrm{~h})$, by which time the larvae had almost ceased their case repairs. Although the experiment was conducted in a lentic condition, we believe that it closely mimicked the near-natural condition, as their microhabitat is typically limited to sluggish flow areas where chemical cues could accumulate. After the experiment, we measured the amount of glass sand that larvae had used for case repair after preserving them in $100 \%$ alcohol (Fig. 1). The amount of glass sand used to repair cases reflected the strength of their response to predatory pressure.

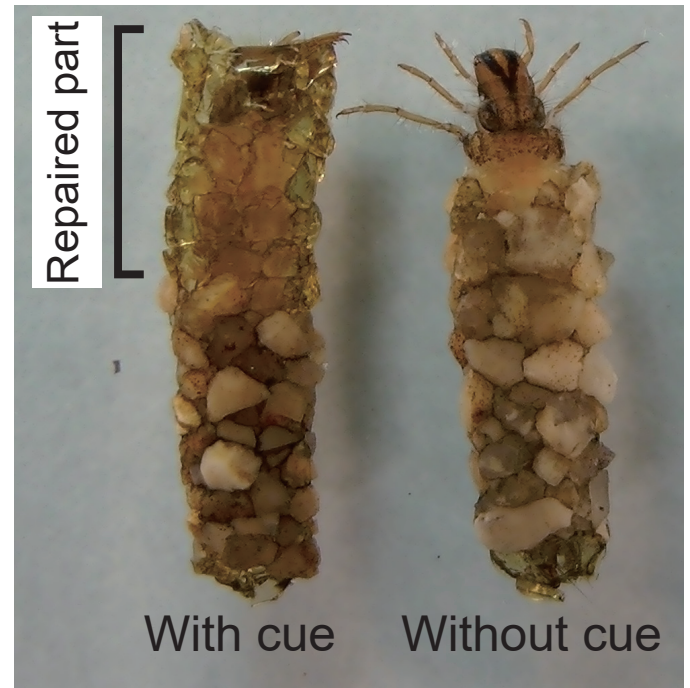

Fig. 1. Perissoneura paradoxa after the case repair experiment. Right-side image, larva not exposed to a predator cue and no sand was added after removing a part of case. Left-side image, larva exposed to a predator chemical cue and it repaired its case faster on adding more sand.

\section{Statistical analysis}

To assess the sympatric effect on larval survivability, we used a generalized linear mixed model (GLMM) analysis with binomial distributions and a logit link using the incubation container as a random effect (Ime4 package, R 3.1.0). We compared binominal data of the number of survivors after one month against the starting number between the sympatric and separated incubation experiments. We also considered the effects of incubation sediment type (glass or ceramic), initial individual number introduced to containers (55 or 110 for Pe. paradoxa), and population locality (Site 4 or 5 for PS. kisoensis). The statistical significance of each correlation model was tested by calculating the deviance of the model with and without explaining the terms. The deviance was assumed to have a chisquare distribution. In a similar fashion, to assess the sympatric effect on larval growth, we used GLMM analysis with gamma errors and a logit link using the incubation container as random effects. Explanatory variables were the same as in the survivability analysis. 
To assess the effect of predator chemical cues on larval case repair, we failed to fit the data to GLMM because of the zero-inflated data of glass sand number used by $P$ e. paradoxa. Thus, we used a Student's t-test to detect differences in length and AD of the anterior end of the case and the amount of glass sand that larvae used for case repair.

\section{RESULTS}

\section{Larval natural habitat}

Table 2 shows the presence or absence of Pe. Paradoxa and Ps. kisoensis larvae and S. leucomaenis in their natural habitat. The caddisfly larvae clearly can only coexist in habitats shared by predatory fish (Site 4, 8 , and 9 ). In contrast, $P$ e. paradoxa and $P$ s. kisoensis existed separately in a fishfree habitat (Site 1, 2, 3, 5, and 6).

\section{Sympatric incubation experiment}

Fig. 2A shows the survivability of $P$ e. paradoxa and $P$ s. kisoensis larvae under sympatric and separated conditions in the absence of S. leucomaenis. For Pe. paradoxa, survivability significantly decreased when the initial individual number was high (GLMM, $z=-2.47, P=0.022$ ). However, there were no significant differences in the survivability for this species between the separated and sympatric treatments $(z=0.458, P=0.65)$ and between the two sediment sand types $(z=1.451, P=0.19)$, indicating that this species was not negatively affected by Ps. kisoensis. In contrast, survivability of Ps. kisoensis significantly decreased in the sympatric treatment (from $86-96 \%$ to $7-30 \%$; GLM, $z=-9.059, P<0.00001)$, but there were no significant
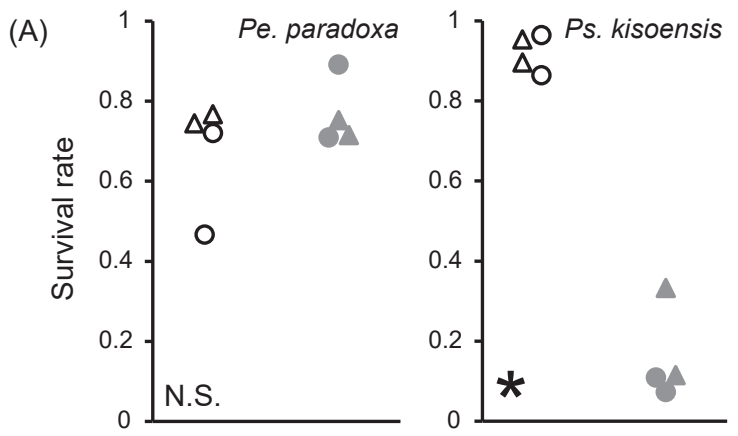

(B)
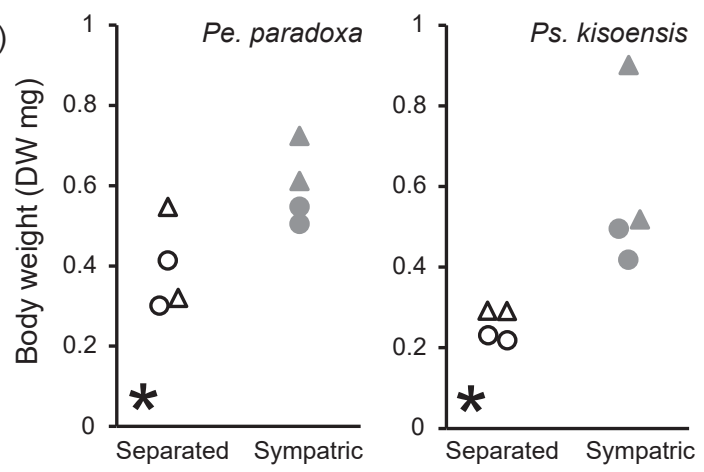

Fig. 2. Survivability (A) and body weight (B) of Perissoneura paradoxa and Psilotreta kisoensis larvae after 1-month incubation without predatory fish. Open symbol: separated condition, Grey symbol: sympatric condition, Triangle: smooth glass sediment condition, and Circle: rough ceramic sediment condition. Each circle corresponds to each incubation deme (mean body weight of a deme is indicated in Fig. 2B). effects caused by sediment sand type $(z=0.815, P=0.415)$ and population locality $(z=0.202, P=0.840)$, indicating that this species was negatively affected by $P$ e. paradoxa.

Fig. 2B shows the body weight of $P$ e. Paradoxa and $P$ s. kisoensis larvae after one month incubation. For both species, larval body weight was higher in the sympatric condition than in the separated condition (GLMM, Pe. paradoxa: $t=7.505, P=0.00028$; Ps. kisoensis: $t=10.33, P<$ $0.00001)$ and higher in glass sediment than in ceramic sediment (Pe. paradoxa: $t=2.786, P=0.021 ;$ Ps. kisoensis: $t=$ $5.20, P=0.0044)$. For $P$ e. paradoxa, body weight was significantly lower when the initial individual number was high $(t=-4.881, P=0.0030)$. For $P$ s. kisoensis, there were no significant effects of population locality $(t=1.17, P=0.24)$.
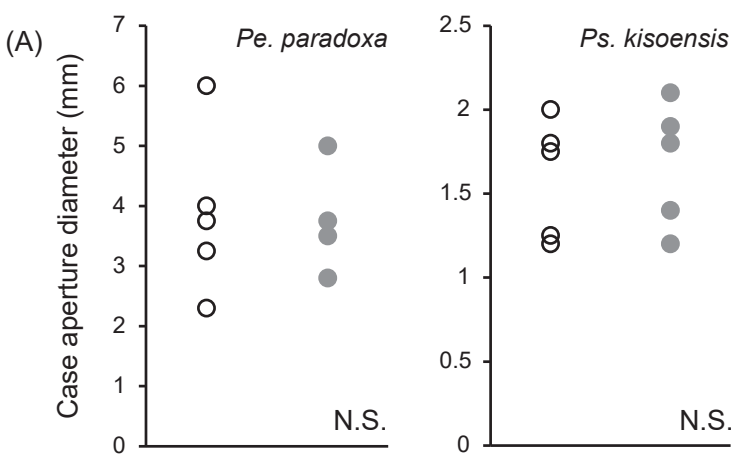

(B)

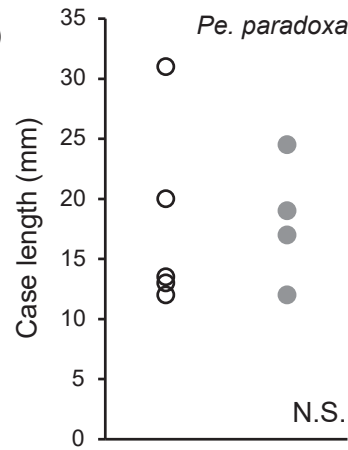

(C)

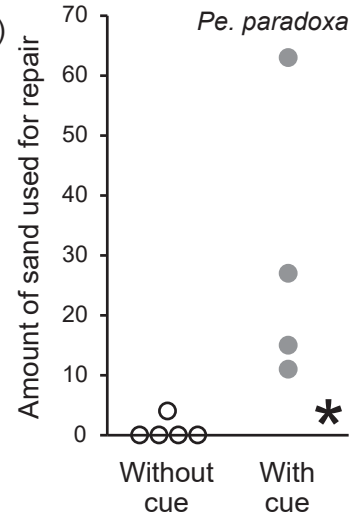

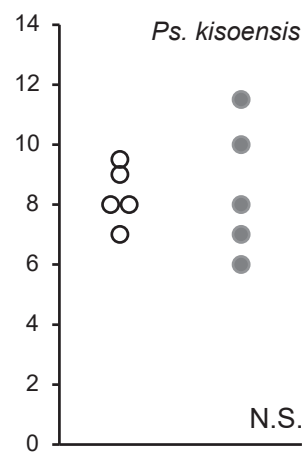

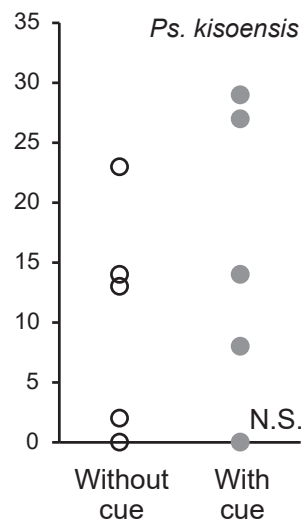

Fig. 3. The length (A) and aperture diameter (B) of natural cases sacrificed for the repair experiment and amount of glass sand used for case repair (C) for Perissoneura paradoxa and Psilotreta kisoensis. Open circles show incubation without exposure to a predatory fish chemical cue and grey circles show incubation with a cue. Each circle corresponds to each individual. 


\section{Case repair in response to $S$. leucomaenis}

Figure $3 A$ and $B$ show length and $A D$ of the natural cases sacrificed for the repair experiment. There were no significant differences in case length (t-test, $P$ e. paradoxa: $\mathrm{df}=7, t=1.2, P=0.45$, Ps. kisoensis: $\mathrm{df}=8, t=0.35, P=$ 0.47 ) and case diameter ( $P$ e. paradoxa: df $=7, t=0.05, P=$ 0.48; Ps. kisoensis: $\mathrm{df}=8, t=0.18, P=0.43$ ) between $S$. leucomaenis cues and the control treatment.

Figure $3 \mathrm{C}$ shows the amount of glass sand used for case repair with $S$. leucomaenis cues and control treatments. For Pe. paradoxa, larvae exposed to $S$. leucomaenis cues added a larger amount of sand to their case (df $=7, t=$ 2.7, $P=0.015$ ). As a result, larva within the $S$. leucomaenis chemical cue treatment clearly enlarged their case compared with those in the control (Fig. 1). On the other hand, $P$ s. kisoensis larvae showed no significant difference in their case repair rate between $S$. leucomaenis cues and control treatments $(\mathrm{df}=8, t=0.75, P=0.24)$.

\section{DISCUSSION}

The competitive exclusion principle dictates that two species competing for common resources cannot coexist at constant population values if other ecological factors remain constant. However, it has been theoretically and empirically established that size-selective predation can be a proximate factor to maintain coexisting stability (Sprules, 1972; Hall et al., 1976; Kesavaraju et al., 2007; Koivisto et al., 2007; Hülsmann et al., 2011). In the present study, we examined how two ecologically similar species of caddisfly larvae with different body sizes can coexist under the influence of predatory pressure.

In natural habitats, Pe. paradoxa and Ps. kisoensis existed separately when predatory pressure was absent (Table 2). In particular, at Sites 5 and 6, the two species did not coexist, even within a $1 \mathrm{~km}$ area. These habitat segregations strongly indicate that these two species cannot coexist in the absence of predatory pressure. The laboratory experiments support this natural distribution pattern. The smaller Ps. kisoensis larvae showed a dramatic decrease in survivability when they coexisted with $P$ e. paradoxa, whereas the survivability of the larger $P$ e. paradoxa did not differ between separated and sympatric incubation. In addition, $P$ e. paradoxa grew faster under the sympatric condition than in the separated condition while maintaining their population. These results indicate that these two species cannot coexist as Pe. paradoxa predates Ps. kisoensis (Fig. 4A). Furthermore, when larvae were exposed to $S$. leucomaenis chemical cues, the case repair speed was much higher for $P e$. paradoxa than it was for Ps. kisoensis (Fig. 3C). Assuming that the response strength of prey reflects potential predation risks from predators, Pe. paradoxa is more vulnerable to predatory fish than Ps. kisoensis. Indeed, it was suggested that the brook trout (Salvelinus fontinalis) selectively preys upon larger benthic macroinvertebrate species from June to September (Bechara et al., 1992). Taken together, Pe. paradoxa strongly preys upon and excludes Ps. kisoensis under predator-free conditions. However, under the presence of a fish predator, predatory exploitation weakens as $P$ e. paradoxa is at a higher predation risk from the fish (Fig. 4B). Under such a condition, the two species are able to coexist in the same habitat.
(A) Absence of predator

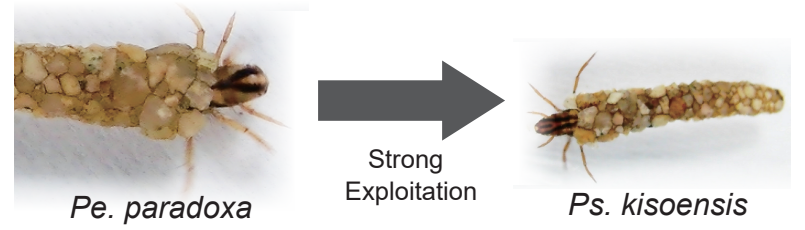

(B) Presence of predator

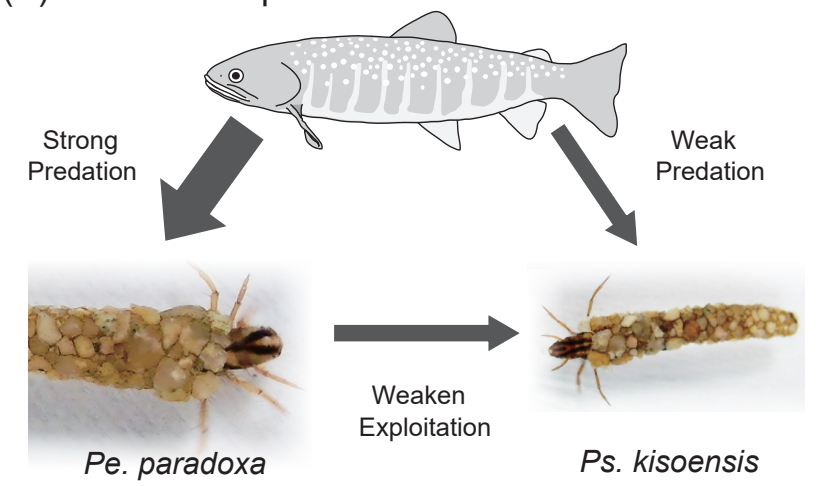

Fig. 4. (A) Interaction between Perissoneura paradoxa and Psilotreta kisoensis without exposure to a predator, and (B) possible triangle interactions among them and predatory fish.

Predators can facilitate the coexistence of multiple competitive prey species both through consumptive and nonconsumptive effects of predation (Yurewicz, 2004; Yamauchi and Yamamura, 2005; Aránguiz-Acuña et al., 2010). The former effect appears when highly active, and thus the faster growing preferred prey suffers higher mortality from the predator, while the latter effect appears when the preferred prey ceases to exploit the less-preferred ones so that they do not encounter a top predator (i.e., growth/predation-risk trade-off; McPeek, 2004). In our case study, the extensive exploitation between Pe. paradoxa and Ps. kisoensis only occurred for two months after they had hatched. In addition, we never observed active Pe. paradoxa predation on Ps. Kisoensis, as their refractive size difference increased in later life stages, because larger larvae cannot intrude into smaller cases (Okano, unpublished). These observations indicate that whether predatory exploitation occurs or not is determined in the early life stage, before $P$ e. paradoxa grows to the preferred prey size for fish. Assuming that the intraguild predation of $P$ e. paradoxa is associated with high activity, fast growth, and longer periods of risk to predation by fish (i.e., reaching the prey size window of fish earlier), $P e$. paradoxa may cease its predatory exploitation of Ps. kisoensis to avoid fish predation, which permits the coexistence of the two species.

Interestingly, Ps. kisoensis also grew larger in the sympatric condition than in the separated condition. It may have been due to minimal resource competition as their population decreased due to predation (Huss et al., 2010). Otherwise, the surviving $P$ s. kisoensis may switch to a fast-growing strategy to escape from the prey size window of $P e$. paradoxa. Indeed, our unpublished data shows that $P S$. kisoensis grows larger as the risk of cannibalism increases.

Although there is no concrete evidence to explain why 
the competitively inferior Ps. kisoensis could exclusively inhabit Sites 5 and 6 without fishes, we think that the reason lies in the difference in case material sizes available at these sites. Perissoneura paradoxa use larger sized sand particles as a case material in accordance with their body size difference. Both species need to use smooth surface sand (e.g., quartz mineral) for their case material to promote respiratory efficiency and thus reduce their metabolic costs (Okano et al., 2010; Okano et al., 2016). Indeed, our results show that the body weight of larvae incubated in rough ceramic sand was lighter than that of the larvae incubated in smooth glass sand. However, the abundance of smooth particles in the natural sediment depended on its mineralogical/ petrological origin. At Sites 5 and 6, the mineral composition was different between the Ps. kisoensis and Pe. paradoxa habitats. The sediment of the Ps. kisoensis habitat contained relatively smooth minerals (quartz and chert) within the size range that could be used as case material (Okano et al., 2011). In contrast, only the unfavorable rough mineral (sand-mudstone) was evident in the size range used by $P e$. paradoxa. The sediment of the $P e$. paradoxa habitat contains smooth surface chert minerals throughout the size range used as a case material (Okano personal observation; the difference of mineralogical component by sediment granularity is described in Okano et al., 2012). Therefore, $P$ e. paradoxa may not be able to invade the neighboring habitat of Ps. kisoensis given the unavailability of favorable case material. Although the superiority of $P$ e. paradoxa (i.e., Ps. kisoensis survival) did not differ between rough and smooth sand habitats in our sympatric-reared experiment, we may be able to test this possibility by rearing larvae in manipulated habitats, mixing the two sand types and manipulating the smooth sand availability for each size fraction.

Three species of Odontoceridae, Psilotreta japonica, Psilotreta kisoensis and $P$ e. paradoxa, are recorded on Honshu Island, Japan. Two species with different body sizes (Pe. paradoxa and Ps. kisoensis) inhabit a similar environment of headwater streams, whereas Ps. japonica, which has a similar body size to Ps. kisoensis, inhabits lowland streams (Tsuda, 1956; Kawase, 2013). In contrast, in North Korea, two closely related species Psilotreta falcula and Psilotreta locumtenens that have a similar body size, copulatory organ, and phenology, and often share the same habitat (Nozaki, personal communication). In this case, other than body-size difference, there should be other factors that permit their coexistence. For instance, differences in the activity rate and effectiveness of antipredator behaviors between two competitive limnephilid caddisfly species led to selective predation by the salamander and further induced reversal in the competitive superiority between them in subalpine wetlands (Wissinger et al., 1996; Wissinger et al., 1999). Therefore, a different predator composition may have resulted in the different odontocerid assemblages between Japan and Korea, due to the conflicting requirements of avoiding different predators.

The protective response of a prey to predator chemical cues can be useful to estimate the potential predation risk because the response strength of the prey reflects the underlying connections with other traits related to vulnerability (Dewitt et al., 1999; Boyero, 2011). Indeed, the magnitude of the prey response is often related to predation risk (Eklöv,
2000; McCarthy and Fisher, 2000; Mowles et al., 2011). Although numerous studies have empirically examined protective plasticity with the view of simple bilateral preypredator interactions or multiple combinations, few studies have considered more than triangular trophic interactions (Relyea, 2000; Trussell et al., 2003). In nature, the responses of prey species are not necessarily reflected at the population level because interspecific interaction is often modified by complex interactions among multiple species. Thus, different predators often create quite different species assemblages (Werner and McPeek, 1994), or extinction of a predator can lead to unexpected cascades of secondary extinctions (Paine, 1966; Sanders et al., 2013). Mowles et al. (2011) showed that a predator chemical cue reversed the competitive superiority between two snail species as they differed in the degree of antipredator response depending on their susceptibility. Therefore, the evaluation of response strength among multiple species is important to understanding complex interspecific interactions.

In conclusion, by evaluating the strength of a protective response, we could explain the possible mechanism behind the coexistence of ecologically similar species in natural habitats. Further studies to confirm their actual vulnerability and the effect of a predator cue on their population dynamics will determine the validity of our hypothesis as a mechanism of coexistence. In addition, we demonstrated the possibility that the coexisting mechanism of odontocerid species in North Korea differed from that in Japan. Psilotreta spp. are widespread throughout East Asia and they have many common ecological characteristics (Dudgeon, 1999). Thus, determining the cause of spatial differences among Psilotreta spp. and Perissoneura provides an excellent model for achieving a better understanding of community structure in relation to speciation and diversification in freshwater ecosystems.

\section{ACKNOWLEDGMENTS}

This work was supported by Grant-in-Aid for Scientific Research (C) from Japan Society for the Promotion of Science (No. 12J01273 \& No. 26840146). We thank Dr. Nozaki for the information on the distribution of a family of Odontoceridae. We thank the editor and two anonymous referees for their helpful and constructive comments. The authors would like to thank Enago (http://www.enago.jp) for the English language review. I would like to express my condolences to the family of Dr. Glenn Wiggins, whose books and research papers introduced me the enjoyment of study of caddisfly ecology.

\section{COMPETING INTERESTS}

The authors have no competing interests to declare.

\section{AUTHOR CONTRIBUTIONS}

JO: conceived and designed the study, performed all experiments, and wrote the MS. SN: Revised the MS. IT: Revised the MS. NO: Revised the MS.

\section{REFERENCES}

Alvarez M, Landeira-Dabarca A, Peckarsky B (2014) Origin and specificity of predatory fish cues detected by Baetis larvae (Ephemeroptera; Insecta). Anim Behav 96: 141-149

Aránguiz-Acuña A, Ramos-Jiliberto R, Bustamante RO (2010) Experimental evidence that induceddefenses promote coexistence ofzooplanktonic populations. J Plankton Res: fbq134 
Bechara JA, Moreau G, Planas D (1992) Top-down effects of brook trout (Salvelinus fontinalis) in a boreal forest stream. Can J Fish Aquat Sci 49: 2093-2103

Bourdeau PE (2012) Morphological defense influences absolute, not relative, nonconsumptive effects in marine snails. Behav Ecol 24: 505-510

Boyero $L$ (2011) Expression of a behaviourally mediated morphology in response to different predators. Ecol Res 26: 1065-1070

Boyero L, Rincón PA, Bosch J (2006) Case selection by a limnephilid caddisfly [Potamophylax latipennis (Curtis)] in response to different predators. Behav Ecol Sociobiol 59: 364-372

Cerezer C, Biasi C, Cogo GB, Santos S (2016) Avoid predation or take risks in basic activities? Predator-prey relationship in subtropical streams between decapods and caddisflies. Mar Freshwater Res 67: 1880-1887

Covich AP, Crowl TA, Hein CL, Townsend MJ, McDowell WH (2009) Predator-prey interactions in river networks: comparing shrimp spatial refugia in two drainage basins. Freshwater Biol 54: 450-465

Dewitt TJ, Sih A, Hucko JA (1999) Trait compensation and cospecialization in a freshwater snail: size, shape and antipredator behaviour. Anim Behav 58: 397-407

Dudgeon D (1999) Tropical Asian streams: zoobenthos, ecology and conservation, vol 1. Hong Kong University Press

Eklöv P (2000) Chemical cues from multiple predator-prey interactions induce changes in behavior and growth of anuran larvae. Oecologia 123: 192-199

Gause G (1934) The Struggle for Existence. Baltimore (MD): Williams and Wilkins. 1970. Criticisms of invalidation of the principle of competitive exclusion. Nature 227: 89

Hall DJ, Threlkeld ST, Burns CW, Crowley PH (1976) The sizeefficiency hypothesis and the size structure of zooplankton communities. Annu Rev Ecol Syst 7: 177-208

Hardin G (1960) The competitive exclusion principle. Science 131: 1292-1297

Hettyey A, Tóth Z, Thonhauser KE, Frommen JG, Penn DJ, Van Buskirk J (2015) The relative importance of prey-borne and predator-borne chemical cues for inducible antipredator responses in tadpoles. Oecologia 179: 699-710

Hülsmann S, Rinke K, Mooij WM (2011) Size-selective predation and predator-induced life-history shifts alter the outcome of competition between planktonic grazers. Funct Ecol 25: 199208

Huss M, Van Kooten T, Persson L (2010) Intra-cohort cannibalism and size bimodality: a balance between hatching synchrony and resource feedbacks. Oikos 119: 2000-2011

Kawase N (2013) Morphological and ecological notes on an endangered caddisfly, Ps. japonica (Banks) (Odontoceridae, Trichoptera). Biol Inland Waters 27: 29-39

Kesavaraju B, Alto BW, Lounibos LP, Juliano SA (2007) Behavioural responses of larval container mosquitoes to a sizeselective predator. Ecol Entomol 32: 262-272

Kishida O, Nishimura K (2004) Bulgy tadpoles: inducible defense morph. Oecologia 140: 414-21

Koivisto E, Huitu O, Korpimäki E (2007) Smaller Microtus vole species competitively superior in the absence of predators. Oikos 116: 156-162

McCarthy TM, Fisher WA (2000) Multiple predator-avoidance behaviours of the freshwater snail Physella heterostropha pomila: responses vary with risk. Freshwater Biol 44: 387-397

McPeek MA (2004) The growth/predation risk trade-off: So what is the mechanism? Am Nat 163: E88-E111

Mowles SL, Rundle SD, Cotton PA (2011) Susceptibility to predation affects trait-mediated indirect interactions by reversing interspecific competition. PLoS One 6: e23068

Okano J, Kikuchi E, Sasaki O (2010) The role of particle surface texture on case material selection and silk lining in caddis flies. Behav Ecol 21: 826-835

Okano J, Kikuchi E, Sasaki O, Ohi S (2011) Geological variation in particle surface-roughness preference in the case-bearing caddisflies. Behav Ecol 22: 1053-1063

Okano J, Kikuchi E, Sasaki O, Ohi S (2012) Mineralogical composition of sediment determines the preference for smooth particles by caddisfly larvae during case construction. Ecol Entomol 37: $426-434$

Okano J, Sasaki O, Kano H (2016) The effects of surface roughness of sediment particles on the respiration of case-bearing caddisfly larvae. Freshwater Sci 35: 611-618

Paine RT (1966) Food web complexity and species diversity. Am Nat 100: $65-75$

Relyea RA (2000) Trait-mediated indirect effects in larval anurans: reversing competition with the threat of predation. Ecology 81: 2278-2289

Reynolds PL, Bruno JF (2013) Multiple predator species alter prey behavior, population growth, and a trophic cascade in a model estuarine food web. Ecol Monogr 83: 119-132

Sanders D, Sutter L, van Veen FJ (2013) The loss of indirect interactions leads to cascading extinctions of carnivores. Ecol Lett 16: $664-9$

Shave CR, Townsend CR, Crowl TA (1994) Anti-predator behaviours of a freshwater crayfish (Paranephrops zealandicus) to a native and an introduced predator. New Zeal J Ecol 18: 1-10

Sprules WG (1972) Effects of size-selective predation and food competition on high altitude zooplankton communities. Ecology 53: 375-386

Taniguchi $\mathrm{H}$, Tokeshi M (2004) Effects of habitat complexity on benthic assemblages in a variable environment. Freshwater Biol 49: 1164-1178

Trussell GC, Ewanchuk PJ, Bertness MD (2003) Trait-mediated effects in rocky intertidal food chains: Predator risk cues alter prey feeding rates. Ecology 84: 629-640

Trussell GC, Ewanchuk PJ, Matassa CM (2006) Habitat effects on the relative importance of trait- and density-mediated indirect interactions. Ecol Lett 9: 1245-1252

Tsuda M (1956) The caddisfly faun (Insecta, Trichoptera) of the Hira-sankei mountain range. Seitai Kontyû, 5: 3-11

Werner EE, McPeek MA (1994) Direct and indirect effects of preadtors on two anuran species along an environmental gradient. Ecology 75: 1368-1382

Wiggins GB (2004) Caddisflies, the underwater architects. University of Tronto Press, Tronto, Canada

Wissinger SA, Sparks GB, Rouse GL, Brown WS, Steltzer H (1996) Intraguild predation and cannibalism among larvae of detritivorous caddisflies in subalpine wetlands. Ecology 77: 2421-2430

Wissinger SA, Whiteman HH, Sparks GB, Rouse GL, Brown WS (1999) Foraging trade-offs along a predator-permanence gradient in subalpine wetlands. Ecology 80: 2102-2116

Yamauchi A, Yamamura N (2005) Effects of defense evolution and diet choice on population dynamics in a one-predator-two-prey system. Ecology 86: 2513-2524

Yokota J, Taira K, Kashiwagi S, Ito S (2013) Life history of characteristics organisms in the Kakita river and the challenges. Report of Riverfront Japan Research Institute 24: 99-109

Yurewicz KL (2004) A growth/mortality trade-off in larval salamanders and the coexistence of intraguild predators and prey. Oecologia 138: 102-111

(Received December 2, 2016 / Accepted May 31, 2017) 